\title{
O tombamento de áreas naturais pelo CONDEPHAAT: marco de inovação e memória da instituição do patrimônio paulista (1976-1995)
}

The landmarking of natural areas by the CONDEPHAAT: mark of innovation and memory of São Paulo's heritage institution (1976-1995)

Felipe Bueno Crispim*

*Licenciado em História pela Universidade Estadual Paulista (Unesp), Campus Assis. Mestre em História pela Universidade Federal de São Paulo (Unifesp). Atuou como pesquisador e documentalista em projetos de identificação, inventário e preservação de acervos documentais e patrimônio cultural. Foi consultor da Diretoria de Patrimônio Artístico e Cultural de Jundiai e parecerista da Revista Arqueologia Pública do Núcleo de Pesquisas e Estudos Ambientais (Nepam), Universidade Estadual de Campinas (Unicamp). É au- tor do livro Entre a Geografia e o Patrimônio: estudo das ações de preservação das paisagens paulistas pelo CONDEPHAAT (19681989), 2016, e membro do Grupo de Trabalho em História Ambiental da Associação Nacional de História (Anpuh), Seção São Paulo, SP. Atualmente é doutorando no Programa de Pós-Graduação em História da Universidade Estadual de Campinas (Unicamp) na linha de pesquisa "História Intelectual, Cultura Visual Patrimônios".

\section{Resumo}

$\mathrm{O}$ artigo enfoca o tombamento de áreas naturais pelo CONDEPHAAT - Conselho de Defesa do Patrimônio Histórico, Arqueológico, Artístico e Turístico. Discute, nesse sentido, as potencialidades e limites do uso do tombamento para a preservação da paisagem natural em suas pluralidades e sentidos, entre os anos de 1970 e 1990, período em que se concentram a maioria das ações desenvolvidas pelo órgão paulista nessa seara de atuação. Propõe como resultado da reflexão a ideia de que a viabilidade do tombamento de áreas naturais deva ser discutida como problemática do presente em constante diálogo interdisciplinar como debate imprescindível na renovação dos estudos sobre as dimensões da ação preservacionista e, em especial, sobre a responsabilidade dos órgãos de preservação do patrimônio cultural na proteção da natureza.

Palavras-chave: Tombamento; CONDEPHAAT; Patrimônio Natural Florianópolis/SC

\section{Abstract}

This article focuses on the landmarking of natural areas by the CONDEPHAAT - Council for the Protection of Historical, Artistic, Archaeological and Tourist Heritage. It discusses the potentialities and limits of landmarking in the preservation of natural landscape in all its aspects between 1970 and 1990, when most actions were developed by this agency in the state of São Paulo. It also proposes the landmarking of natural areas should be discussed as a current issue, in constant interdisciplinary dialogue as an indispensable debate in the renewal of studies on preservation, and especially under the responsibility of cultural heritage.

Keywords: Landmarking; CONDEPHAAT; Natural Heritage. 


\section{Introdução}

\section{$\mathbf{P}$} a preservação das areas naturais como patrimônio cultural é um desafio de fôlego interdisciplinar que pressupõe o rompimento com clássicos paradigmas orientadores da prática preservacionista brasileira em especial a ideia, erroneamente difundida ao longo do tempo, de que os órgãos de preservação não devem se responsabilizar pela proteção da natureza. No intuito de contribuir para a superação de tal desafio o presente texto debate a experiência do Conselho de Defesa do Patrimônio Histórico, Arqueológico, Artístico e Turístico do Estado de São Paulo - CONDEPHAAT na proteção de espaços naturais procurando demonstrar a sua atualidade e viabilidade como prática de preservação.

Compreendendo a instituição do patrimônio em São Paulo como problemática do tempo presente e arena de embates e controvérsias incessantes entre intelectuais, sociedade civil organizada e os grupos das mais diferentes matrizes ideológicas, considerando assim o tombamento das áreas naturais pelo CONDEPHAAT como memória técnico-científica e marco de inovação das práticas preservacionistas paulistas.

A partir desse viés apresentamos um breve panorama crítico dos sentidos de ser da patrimonialização da natureza na trajetória da política federal de preservação do patrimônio cultural, tema debatido de forma pormenorizada por Mongelli (2011), Magalhães (2015) e Pereira (2018). Em seguida, analisamos o tombamento de áreas naturais em São Paulo entre meados da década de 1970 e 1990 considerando para isso suas características inovadoras na ampliação do conceito de tombamento tal qual é definido desde sua criação em 1937, para a proteção de espaços naturais mediante o reconhecimento dos valores científicos e ecológicos oriundos de uma abordagem geográfica da paisagem. 
Nessa inovação acreditamos estar inscrita uma singularidade da instituição do patrimônio paulista: a influência dos saberes acadêmicos na definição de diretrizes de atuação para o CONDEPHAAT, cujo colegiado contou desde 1975 com a presença crescente de membros das universidades estaduais paulistas - USP, Unesp e Unicamp nas áreas da Arquitetura, História, Geografia, Arqueologia, Etnografia e Ciências Sociais. (RODRIGUES, 2000).

Imbricada a essa singularidade desenvolvese o fio condutor da nossa investigação - a ideia de que o tombamento das áreas naturais pelo CONDEPHAAT precisa ser incorporado a memória técnico científica paulista no sentido de subsidiar a renovação do debate sobre a responsabilidade dos órgãos de preservação do patrimônio natural na preservação da natureza, discussão de caráter atual e urgente.

\section{Patrimônio e Paisagem nas políticas de preservação brasileiras}

A proteção dos espaços naturais pelos órgãos de preservação do patrimônio cultural no Brasil é prevista no decreto-lei 25 de 1937 responsável pela criação da figura jurídica do tombamento e pela organização do Serviço do Patrimônio Histórico e Artístico Nacional - SPHAN ${ }^{1}$. Caberia ao poder público, nos termos do decreto, proteger os monumentos naturais, sítios e paisagens, conforme inscrição em livro de tombo competente:
Art. $1^{\circ}$ Constitui o patrimônio histórico e artístico nacional o conjunto dos bens móveis e imóveis existentes no país e cuja conservação seja de interesse público, quer por sua vinculação a fatos memoráveis da história do Brasil, quer por seu excepcional valor arqueológico ou etnográfico, bibliográfico ou artístico.

$\S 1^{\circ}$ Os bens a que se refere o presente artigo só serão considerados parte integrante do patrimônio histórico e artístico nacional, depois de inscritos separada ou agrupadamente num dos quatro Livros do Tombo, de que trata o art. $4^{\circ}$ desta lei.

$\S 22^{\circ}$ Equiparam-se aos bens a que se refere o presente artigo e são também sujeitos a tombamento os monumentos naturais, bem como os sítios e paisagens que importe conservar e proteger pela feição notável com que tenham sido dotados pela natureza ou agenciados pela indústria humana (BRASIL, 1937)

Os valores histórico e artístico atribuídos aos monumentos naturais, sítios e paisagens seriam definidos a partir de sua capacidade de equiparar-se ao artifício humano seja por suas características naturais como "feições notáveis dotadas pela natureza" seja como resultado da ação humana sobre o espaço natural "agenciado pela natureza". Possibilitava assim que fossem tombadas porções do território nacional aonde a presença humana não se fazia predominante ou visível, como era o caso dos sítios e paisagens cuja "feição notável" era dotada pela natureza. Patrimônio Histórico e Artístico Nacional (IPHAN), denominação vigente até os dias atuais. 
Tratava-se da concepção usual à época que relacionava a noção de patrimônio ao campo da história da arte, da estética e da visualidade compreendendo a natureza antes de tudo por meio do olhar de um observador - agente do Estado, cujo poder discricionário identificava e legitimava os valores histórico e artístico capazes de justificar o ato do tombamento que, no caso dos elementos naturais deveria obrigatoriamente atender ao requisito da excepcionalidade e da beleza cênica.

Os procedimentos relativos à identificação e valoração dos bens culturais nos primeiros anos da institucionalização do patrimônio no Brasil tiveram grande influência da legislação francesa, cujos princípios serviram de base e fundamentação para muitas legislações relativas à prática preservacionista na Europa e na América Latina. Na França a partir de 1930 a já consagrada lei dos monumentos históricos de 1913, passou a contar com a possibilidade de proteção dos monumentos naturais e dos sítios de caráter artístico, histórico, científico, legendário ou pitoresco².

A esse respeito aponta a filósofa e estudiosa da paisagem Anne Cauquelin (2007) que a definição de "sítio" e "paisagem" elaborada em 1930 pelo Ministério da Instrução Pública e das Belas Artes da França destaca a ambiguidade, reunindo em uma só fórmula os dois objetos antagônicos da noção de paisagem: o ordenamento construído e o princípio eterno, enunciando assim uma perfeita equivalência entre arte e a natureza:

(...) de um lado, restituir a paisagem como única forma de torná-la visível, de outro lado, desdobrá-la em direção ao princípio inalterável da natureza, apagando então a ideia de sua possível construção. Confusão bem marcada no fluxo de noções de "sítio", de "meio ambiente", de "ordenamento" ou de "integração". Pois os mesmos que querem salvaguardar a natureza da paisagem como dado primitivo, se dedicam também a proteger os "sítios" depositários de uma certa memória, histórica e cultural. Ora o "sítio", o que permanece ali, designa tanto o monumento (esse arco, essa cidade antiga, esse vestígio) quanto a forma geológica singular que intervém num meio natural. Nessa ótica, a paisagem é um "monumento natural de caráter artístico"; a floresta uma "galeria de quadros naturais, um museu verde". (CAUQUELIN, 2007, p.40-41)

Para além da influência das leis de proteção do patrimônio na França o nosso decreto lei 25/37 teve suas bases assentadas sobre $o$ anteprojeto de Mário de Andrade redigido ainda em 1936 a pedido do então ministro da Educação e Saúde, Gustavo Capanema. Como apontam Chuva (2009) e Fonseca (2009) em seu projeto de lei para a instituição do patrimônio, Andrade compreendia a noção de arte como conceito unificador de uma ideia de Patrimônio Artístico Nacional como sendo:

(...) todas as obras de arte pura ou de arte aplicada, popular ou erudita, nacional ou 
estrangeira, pertencentes aos poderes públicos, a organismos sociais e a particulares nacionais, a particulares estrangeiros residentes no Brasil (...) deverão pertencer pelo menos a uma das oito categorias seguintes: 1. Arte arqueológica; 2. Arte ameríndia; 3. Arte popular; 4. Arte histórica; 5 . Arte erudita nacional; 6 . Arte erudita estrangeira; 7. Artes aplicadas nacionais; 8. Artes aplicadas estrangeiras. (ANDRADE, 1980, p. 90-92)

A paisagem é compreendida dessa forma como parte de uma ou mais das categorias de arte estabelecidas por Andrade sempre como expressão do engenho humano:

(...) determinados lugares da natureza, cuja expansão florística, hidrográfica ou qualquer outra foi determinada definitivamente pela indústria humana dos Brasis, como cidades lacustres, canais, aldeamentos, caminhos, grutas trabalhadas, etc. (ANDRADE, 1980, p. 92)

Para Ribeiro (2007) a noção de paisagem de Mário de Andrade era tributária da etnografia, a entendendo assim como um construto da arte popular em sentido amplo. Através do tombamento de paisagens, os bens materiais impressos no espaço pelo trabalho coletivo, desassociados daquilo que considera como arte erudita, poderiam ser reconhecidos como patrimônio e preservados. (RIBEIRO, 2007, p. 71)

Já o texto definitivo publicado em 30 de novembro de 1937 como Decreto Lei No 25 com sensíveis alterações de âmbito e conteúdo no que tange ao caráter eminentemente artístico do patrimônio nacional conforme estabelecia o anteprojeto de Mário de Andrade, optou pela noção de "patrimônio histórico e artístico nacional" criando dentre os livros de tombo do então SPHAN o Arqueológico, Etnográfico e Paisagístico cuja existência, apesar da pouca precisão de conceitos e definições, demarcou um lugar político para a inscrição dos espaços naturais como patrimônio nacional.

Apesar dessa conformação institucional o patrimônio paisagístico não encontrou uma definição clara durante a trajetória de formação do acervo de bens culturais tombados pelo IPHAN, sendo difícil a tarefa de analisar os critérios utilizados desde a fundação do órgão em 1937 para a inscrição de bens no livro de tombo Arqueológico, Etnográfico e Paisagístico, lugar aonde supostamente deveriam estar reunidas as tipologias de bens relacionados ao mundo natural e ao ambiente não construído. (RIBEIRO, 2007)

Como afirma Magalhães (2015) o patrimônio paisagístico protegido pelo Iphan até pelo menos os anos de 1950 teria sido selecionado a partir de um convênio firmado em 1938 entre o órgão então dirigido por Rodrigo Melo Franco de Andrade e o Museu Nacional à época sob a presidência de Heloisa Alberto Torres. Essa parceria fez com que boa parte dos bens inscritos no livro de tombo Arqueológico, Etnográfico e Paisagístico fossem identificados mediante critérios das ciências 
naturais como a botânica e a antropogeografia, na chave científica, antropológica-botânica e não necessariamente do paisagismo. (MAGALHÃES, 2015, p. 222)

Para além desse convênio estabelecido por meio da atuação dos membros do Museu Nacional como Raimundo Lopes e Alberto Childe no Conselho Consultivo do Iphan, no anos de 1980 seria firmada uma parceria do órgão com o Instituto Brasileiro de Desenvolvimento Florestal (IBDF), autarquia do Ministério do Meio Ambiente, para a realização de um Plano Geral de orientação da área do Jardim Botânico do Rio de Janeiro, documento que normatizava a cooperação dos dois órgãos na revitalização e modernização do Jardim Botânico carioca estabelecendo também um regime de estreita, intensa e mútua colaboração entre as partes na realização de estudos, pesquisas, projetos e investimentos que visem a restauração, conservação e proteção de sítios históricos, arqueológicos e paisagísticos encontrados nas unidades de conservação administradas pelo Instituto. (PEREIRA, 2018 p. 63)

O novo convênio trouxe a possibilidade de cooperação entre dois órgãos que, apesar de atuarem na proteção dos espaços naturais de forma complementar e não conflitante, já que regidos por legislações distintas, estiveram historicamente distantes. A essa inovação se seguiria a formação da Coordenação de Patrimônio Natural e Arqueológico sob a direção dos arquitetos Carlos Alberto Xavier e Carlos de Moura Delphim, extinto em 1990 quando da criação do IBPC e reorganizado apenas entre 2009 e 2013 sob a denominação de Coordenação Geral do Patrimônio Natural. (PEREIRA, 2018, p. 63)

Considerando o cenário nacional em que se destacam a marginalidade e a falta de definições precisas no tratamento do tema da proteção dos espaços naturais pelas políticas de preservação adentramos ao debate do caso paulista e suas peculiaridades em relação ao cenário nacional, objeto da nossa análise mais apurada.

\section{O tombamento de áreas naturais pelo CONDEPHAAT}

Em sua tese de doutorado em geografia humana "A construção do patrimônio natural", Simone Scifoni (2006) realiza um estudo pioneiro sobre o tombamento da Serra do Mar em São Paulo demostrando seu papel na produção do espaço geográfico no litoral norte, caracterizado pela crescente urbanização, sendo a preservação da Serra um atrativo para o mercado imobiliário do tipo veraneio e para a manutenção da divisão espacial do trabalho da metrópole paulistana. (SCIFONI, 2006, p. 5)

A análise empreendida pela autora compreende a trajetória do termo patrimônio natural como categoria de inclusão de bens na lista do Patrimônio Mundial da Unesco desde 1972 para 
os espaços naturais reconhecidos pela agência internacional mediante o reconhecimento dos valores de excepcionalidade e universalidade. Mas é no âmbito das experiências locais de preservação que o conceito de patrimônio natural ganha maior dinamismo e expressividade - quando utilizado para referenciar a luta de populações e comunidades em prol da preservação da natureza, uma natureza socialmente apropriada e vivida no cotidiano dos grupos sociais. (SCIFONI, 2006 p. 115)

É nessa segunda acepção do patrimônio natural que reside a experiência do CONDEPHAAT na preservação das áreas naturais, tombamentos que se tornariam paradigmáticos não só pelo seu caráter inédito marcado pelo uso de conceitos oriundos do campo da geografia na identificação e valoração de áreas naturais, mas também e sobretudo, pelo fato dos tombamentos derivarem quase sempre de pedidos da sociedade civil e da comunidade científica paulista que encontraria no patrimônio um lugar de expressão das práticas cidadãs no contexto da abertura política e da redemocratização do país. (CRISPIM, 2016)

O CONDEPHAAT passava a contar a partir de 1976 com a presença de geógrafos da Universidade de São Paulo que, junto com os arquitetos da Faculdade de Arquitetura e Urbanismo da mesma universidade, formaram um ambiente propício ao surgimento de práticas de salvaguarda constituídas sob o olhar da geografia como também da valorização de tipologias ainda não contempladas pelo tombamento como os bens relativos à imigração de diferentes matrizes étnicas, o patrimônio de matriz africana e indígena e os estilos arquitetônicos representativos dos séculos XIX e XX com especial destaque para o ecletismo. (RODRIGUES, 2000)

Nesse cenário renovador em termos conceituais e dos diálogos que se teciam entre ambientalistas, geógrafos e arquitetos através do campo do patrimônio foram criadas condições favoráveis para o surgimento de uma concepção de patrimônio natural tributaria dos conceitos de paisagem e território oriundos da geografia e que pela primeira vez influenciavam a pauta patrimonial fazendo do tombamento um instrumento da gestão do território e portanto, das tensões fundiárias características das áreas naturais, sobretudo aquelas limítrofes dos grandes centros urbanos.(CRISPIM, 2016)

Sendo o tombamento o único instrumento jurídico brasileiro que possibilitava o reconhecimento do interesse público sobre $\circ$ privado sem a consequência da desapropriação, geógrafos como Aziz Nacib Ab'Saber conceberam diretrizes de preservação de grandes áreas naturais tendo como referência a ideia de que a conservação do ambiente natural se viabilizava através da consagração dos usos sociais e dos valores culturais, científicos, ecológicos identificados nessas áreas aonde a presença humana conforma paisagens de alta seletividade espacial como por exemplo a Serra do Mar, da Cantareira ou mesmo o Japi, ladeadas por cidades de médio e grande porte em franco processo de expansão de suas manchas urbanas desde pelo os anos de 1950. (AB SABER, 1986) 
Nesses locais, pensava Ab'Saber, o instrumento do tombamento poderia permitir que desenvolvimento e preservação caminhassem juntos. Considerando-se a ocupação humana de longa data como a dos pequenos povoados, regiões de agricultura familiar, comunidades caiçaras, aldeias indígenas e núcleos quilombolas entre outras manifestações da ação antrópica como também os próprios núcleos urbanos conformados na paisagem, seria possível preservar a natureza como referência cultural, científica, ecológica e memória dos diferentes grupos formadores da sociedade brasileira. Isto é, as áreas naturais como documentos de cultura.

Nada mais digno de ser inscrito no livro dos patrimônios naturais básicos de um país do que os espaços de suas paisagens de exceção. Seus tecidos ecológicos mais delicados e representativos. Os remanescentes de seus ecossistemas continentais ou marinhos. A rigor, tudo aquilo que escapa da banalidade topográfica e paisagística, sublinhado por um tipo qualquer de excepcionalidade ecológica e biótica mereceria, desde o início, uma proteção legal, por uma modalidade qualquer de disposição estatutária. Para tanto, a imaginação preservacionista foi muito fértil, desdobrando a tipologia dos instrumentos de proteção da natureza: parques nacionais, parques estaduais, parques municipais, reservas florestais, reservas biológicas, estações ecológicas, santuários e áreas de preservação da vida silvestre. Para não falar das reservas indígenas, que se constituem em um tipo de espaço natural e antropológico, defendido pela própria Constituição. (AB'SABER, 1986, p. 7)
A especificidade do uso do tombamento para a preservação das áreas naturais tinha critérios específicos muito claros e delimitados, nesse sentido, por exemplo, dispensava-se o uso do tombamento para a preservação de áreas de difícil monitoramento e que estivessem distantes de manchas urbanas significativamente capazes de afetar a biodinâmica dos processos ecológicos, hidrológicos e fisiográficos constitutivos de sua formação. Espaços que já contem com outra tutela jurídica de preservação, desde que essa seja adequada à efetivação da salvaguarda do espaço, também estavam fora dos critérios estabelecidos para o tombamento.

Paradoxalmente os espaços mais indicados para um tombamento situam-se próximos de áreas altamente humanizadas, sujeitas a uma forte e irreversível pressão da especulação imobiliária (...) não é por outra razão que a fachada atlântica de São Paulo em setores não muito distantes da grande metrópole paulistana, tenha sido pioneira nos esforços para o tombamento de alguns patrimônios naturais básicos: Serra do Mar, Juréia, Pedra Grande, Cantareira, Jaraguá, Boturuna e Cabeceira do Rio Tietê. (AB'SABER)

\section{- CONDEPHAAT, entre a geografia e o patrimônio}

Composto inicialmente de nove cadeiras representativas $^{3}$, o CONDEPHAAT teve seu corpo de conselheiros ampliado a partir de 1976 pelo decreto 7516/76 passando a contar com as cadeiras dos departamentos de História da 
Arquitetura e Geografia da Universidade de São Paulo, Comissão Estadual de Artes Plásticas e Conferência Nacional dos Bispos do Brasil (CNBB) totalizando assim treze representações.

A ampliação do corpo de conselheiros respondia à crescente necessidade de atuação especializada nos diversos campos de saber que o mundo do patrimônio passaria a permear a partir dos anos de 1970. Já em 1974 um relatório de atividades organizado pelo secretário executivo do CONDEPHAAT Ruy de Azevedo Marques apontava o caráter amadorístico dos critérios de seleção até então adotados como sendo o principal entrave para a renovação das práticas do órgão. (RODRIGUES, 2000, p.55)

Acreditava-se que o conhecimento científico das áreas de história da arquitetura e geografia dentre outras, possibilitaria a adoção de critérios objetivos para a seleção de bens culturais revelando a complexidade teórica e técnica do campo do patrimônio que para muito além do saber erudito, poderia ganhar abrangência social e dimensão cultural para o conjunto da sociedade. Tais anseios tornaram-se em parte viáveis a partir de 1975 quando o CONDEPHAAT passou a integrar a Secretaria de Cultura, Ciência e Tecnologia, pasta que substituía a antiga Secretaria de Cultura, Esportes e Turismo tendo como seu primeiro dirigente o bibliógrafo e industrial José Mindlin que então procurou recepcionar as demandas apontadas por Ruy de Azevedo Marques em seu relatório. (RODRIGUES, 2000)
A ampliação do Conselho foi então efetivada em maio de 1976 durante a gestão de Nestor Goulart Reis Filho. A cadeira do Departamento de História da Arquitetura e Estética do Projeto da Faculdade de Arquitetura e Urbanismo (FAU/ USP) seria ocupada por Benedito Lima de Toledo e, representando o Departamento de Geografia da Faculdade de Filosofia, Letras e Ciências Humanas (FFLCH), Aziz Ab'Saber. Tal ampliação marca um período de renovação das práticas do órgão quando os saberes acadêmicos e as discussões internacionais sobre preservação ganham espaço de atuação permitindo a construção de novos olhares para novos objetos de preservação.

É desse período a consolidação das ideias de "patrimônio cultural", "patrimônio natural" e "bem cultural" que passam a integrar o cotidiano do campo da preservação no Brasil. Essas concepções vinham se constituindo em âmbito internacional e tornam-se correntes nos anos de 1970 como se vê na $17^{\text {a }}$ Conferência Geral da Unesco realizada em Paris em novembro de 1972 quando são definidos os conceitos de patrimônio cultural e natural no âmbito do Comitê do Patrimônio Mundial.

No plano das políticas ambientais também em 1972 ocorreu a Conferência sobre Meio Ambiente Humano em Estocolmo, Suécia considerada um marco na emergência da consciência ambientalista em caráter planetário (MCCORMICK, 1992, p. 53) 
No Brasil essa Conferência favoreceu a criação da Secretaria Especial do Meio Ambiente (SEMA) fundada em 1973 e dirigida pelo jurista Paulo Nogueira Neto que dividiria atribuições com o Instituto Brasileiro de Desenvolvimento Florestal (IBDF), atualmente incorporados pelo Instituto Chico Mendes de Conservação da Biodiversidade (ICMBio) do Ministério do Meio Ambiente. (NOGUEIRA-NETO, 2009)

A conjuntura internacional $\mathrm{e}$ as discussões sobre meio ambiente ressoavam nos órgãos de patrimônio cultural, muito embora seja perene até os dias atuais a clássica separação entre natureza e cultura nos termos da $17^{\text {a }}$ Conferência da Unesco de 1972 que definiu patrimônio natural como sendo:

Os monumentos naturais constituídos por formações físicas e biológicas ou por grupos de tais formações com valor universal excepcional do ponto de vista estético ou científico; As formações geológicas e fisiográficas e as zonas estritamente delimitadas que constituem habitat de espécies animais e vegetais ameaçadas, com valor universal excepcional do ponto de vista da ciência ou da conservação; Os locais de interesse naturais ou zonas naturais estritamente delimitadas, com valor universal excepcional do ponto de vista da ciência, conservação ou beleza natural. (UNESCO, 1972, art. 2)

Em 1974 na FAU/USP um curso de especialização foi ministrado contando com a presença do museólogo e historiador da arte Hugues de Varine-Bohan. O curso tornou-se um lugar de memória das práticas de preservação do patrimônio introduzindo conceitos inovadores de cultura, meio ambiente e preservação. (RODRIGUES, 2000)

O "curso de 1974", como ficou conhecido, foi promovido por deliberação do Compromisso de Brasília de 1970 que estabeleceu a criação de cursos de pós-graduação sobre patrimônio cultural e restauração de obras de arte como prioridade através de parcerias entre os órgãos de preservação e as universidades. (NASCIMENTO, 2016, p. 207)

No CONDEPHAAT a partir desse contexto uma nova perspectiva de atuação ganhou espaço incorporando-se definições inovadoras de patrimônio que concebiam a preservação como uma prática de atribuição de valor o que negava a ideia, fruto de uma visão erudita de cultura, de que os bens culturais possuíam valores imanentes que deveriam ser reconhecidos pelo olhar técnico dos órgãos de preservação:

Em meio a contínuas contradições, o CONDEPHAAT adotaria novos objetos de proteção, escolha reveladora de uma concepção de ação preservacionista até então inédita, que colocava como finalidade última o homem, produtor de cultura. Sob a influência de Aziz Ab'Saber, representante do Departamento de Geografia da Universidade de São Paulo, o tombamento passou a ser adotado como medida de proteção ao meio ambiente e, por essa vertente, o patrimônio passaria a ser entendido como elevação da qualidade de vida' (RODRIGUES, 2000, p.80) 
É a partir desse ideário que a preservação de áreas naturais tornou-se uma diretriz de ação do patrimônio paulista. A escala monumental e a concepção de recanto paisagístico atribuído à natureza a partir de seu potencial turístico dá lugar à escala geográfica a partir da qual são atribuídos valores científicos e éticos à natureza como vetor de qualidade de vida e equilíbrio do meio ambiente, constatado o grau alarmante de devastação em que se encontravam os recursos naturais.

\section{A formulação de diretrizes específicas para a proteção das áreas naturais}

Como representante do Departamento de Geografia da USP Ab'Saber ofereceria ao Conselho o texto Diretrizes para uma política de preservação das reservas naturais do estado de São Paulo posteriormente publicado na integra na revista daquele departamento:

(...) esforçamo-nos para tratar as complexas questões envolvidas dentro de uma linha de pensamento que comporta uma busca de critérios racionais, suficientemente objetivos, para tentar ajudar a salvação dos remanescentes de uma natureza agredida e desfigurada. E, assim, minimizar os defeitos de organização básica do espaço territorial, com vistas ao benefício de todos os habitantes e grupos sociais do Estado de São Paulo. Numa contingência de alto nível de valorização das terras e redução sensível de espaços disponíveis e não comprometidos, torna-se imprescindível uma política seletiva de identificação de áreas, a fim de viabilizar a proteção e permanência de alguns quadros significativos da natureza no interior do universo paisagístico e ecológico do território paulista. (AB'SABER, 1977, p. 24)

Nas Diretrizes procurava-se sintetizar conceitoschave como espaço total e paisagem no intuído de mobilizá-los para a defesa do patrimônio natural paulista. $O$ texto estabelecia três níveis de ação: em caráter emergencial e prioritário estavam as áreas críticas e ecologicamente estratégicas correspondentes a filtros da biosfera; em segundo plano, as paisagens de exceção (morros testemunho, mares de pedras, lapas e cavernas etc.) e finalmente as paisagens de substituição como hortos florestais, jardins e parques para as quais projetava fins turísticos e recreativos.

A porção paulista da Serra do Mar, a Serra do Japi e diversas outras áreas limítrofes aos grandes centros urbanos de São Paulo enquadravam-se entre as tais áreas críticas, dando-lhes prioridade na execução da política de áreas naturais o que culminaria entre os anos de 1970 e 1980 na definição das linhas de ação do CONDEPHAAT na composição do quadro de referência da ação de salvaguarda das paisagens paulistas. 


\section{Áreas Naturais tombadas pelo CONDEPHAAT (em ordem cronológica)}

\begin{tabular}{|c|c|c|c|}
\hline Bem tombado & Município(s) & Resolução & Livro do Tombo \\
\hline Bosque dos Jequitibás & Campinas & 09/04/1970 & $\begin{array}{l}\text { Arqueológico, Etnográfico e } \\
\text { Paisagístico }\end{array}$ \\
\hline Parque das Monções & Porto Feliz & 20/03/1972 & Histórico \\
\hline $\begin{array}{l}\text { Estrada do Lorena, } \\
\text { monumentos de Victor } \\
\text { Dubugras e Área de mata } \\
\text { circundante }\end{array}$ & $\begin{array}{l}\text { Cubatão e São Bernardo do } \\
\text { Campo (Estrada Velha de } \\
\text { Santos) }\end{array}$ & $11 / 08 / 1972$ & Histórico \\
\hline Pedreira de Varvitos & Itu & 18/03/1974 & $\begin{array}{l}\text { Arqueológico, Etnográfico e } \\
\text { Paisagístico }\end{array}$ \\
\hline Parque da Independência & São Paulo & 02/04/1975 & Histórico \\
\hline $\begin{array}{l}\text { Horto e Museu Edmundo } \\
\text { Navarro de Andrade }\end{array}$ & Rio Claro & 09/12/1977 & $\begin{array}{l}\text { Arqueológico, Etnográfico e } \\
\text { Paisagístico }\end{array}$ \\
\hline Maciço da Juréia e rio Verde & Iguape & $25 / 07 / 1979$ & $\begin{array}{l}\text { Arqueológico, Etnográfico e } \\
\text { Paisagístico }\end{array}$ \\
\hline $\begin{array}{l}\text { Reserva Florestal do Morro } \\
\text { Grande }\end{array}$ & Cotia & 02/06/1981 & $\begin{array}{l}\text { Arqueológico, Etnográfico e } \\
\text { Paisagístico }\end{array}$ \\
\hline Jardim da Luz & São Paulo & 08/08/1981 & $\begin{array}{l}\text { Arqueológico, Etnográfico e } \\
\text { Paisagístico }\end{array}$ \\
\hline Parque Trianon & São Paulo & 13/05/1982 & $\begin{array}{l}\text { Arqueológico, Etnográfico e } \\
\text { Paisagístico }\end{array}$ \\
\hline $\begin{array}{l}\text { Reserva Florestal da Fundação } \\
\text { José Pedro de Oliveira }\end{array}$ & Campinas & 03/02/1983 & $\begin{array}{l}\text { Arqueológico, Etnográfico e } \\
\text { Paisagístico }\end{array}$ \\
\hline $\begin{array}{l}\text { Unidades Habitacionais de } \\
\text { Picinguaba }\end{array}$ & Ubatuba & 01/03/1983 & $\begin{array}{l}\text { Arqueológico, Etnográfico e } \\
\text { Paisagístico }\end{array}$ \\
\hline Parque Estadual do Jaraguá & São Paulo & 04/02/1983 & $\begin{array}{l}\text { Arqueológico, Etnográfico e } \\
\text { Paisagístico }\end{array}$ \\
\hline $\begin{array}{l}\text { Serra do Japi, Guaxinduva e } \\
\text { Jaguacoara }\end{array}$ & $\begin{array}{l}\text { Jundiaí, Cabreúva, Pirapora do } \\
\text { Bom Jesus }\end{array}$ & 08/03/1983 & $\begin{array}{l}\text { Arqueológico, Etnográfico e } \\
\text { Paisagístico }\end{array}$ \\
\hline $\begin{array}{l}\text { Serra de Atibaia ou de } \\
\text { Itapetininga }\end{array}$ & $\begin{array}{l}\text { Atibaia, Bom Jesus dos } \\
\text { Perdões }\end{array}$ & 06/07/1983 & $\begin{array}{l}\text { Arqueológico, Etnográfico e } \\
\text { Paisagístico }\end{array}$ \\
\hline Serra da Boturuna & $\begin{array}{l}\text { Pirapora do Bom Jesus e } \\
\text { demais municípios }\end{array}$ & 04/08/1983 & $\begin{array}{l}\text { Arqueológico, Etnográfico e } \\
\text { Paisagístico }\end{array}$ \\
\hline $\begin{array}{l}\text { Reserva Estadual da Cantareira } \\
\text { e Horto Florestal }\end{array}$ & $\begin{array}{l}\text { Caieiras, Mairiporã, São Paulo e } \\
\text { Guarulhos }\end{array}$ & 04/08/1983 & $\begin{array}{l}\text { Arqueológico, Etnográfico e } \\
\text { Paisagístico }\end{array}$ \\
\hline Morro do Botelho & Guarujá & 01/08/1984 & $\begin{array}{l}\text { Arqueológico, Etnográfico e } \\
\text { Paisagístico }\end{array}$ \\
\hline $\begin{array}{l}\text { Serra do Mar e de } \\
\text { Paranapiacaba }\end{array}$ & Apiaí e demais municípios & 06/06/1985 & $\begin{array}{l}\text { Arqueológico, Etnográfico e } \\
\text { Paisagístico }\end{array}$ \\
\hline
\end{tabular}


Felipe Bueno Crispim O tombamento de áreas naturais pelo CONDEPHAAT: marco de inovação e memória da instituição do patrimônio paulista (1976-1995)

\begin{tabular}{|c|c|c|c|}
\hline Bem tombado & Município (s) & Resolução & Livro do Tombo \\
\hline $\begin{array}{l}\text { Morros do Monduba, do Pinto e } \\
\text { do Icanhema }\end{array}$ & Guarujá & 10/12/1985 & $\begin{array}{l}\text { Arqueológico, Etnográfico e } \\
\text { Paisagístico }\end{array}$ \\
\hline $\begin{array}{l}\text { Parque da Aclimação e Áreas } \\
\text { Verdes Adjacentes }\end{array}$ & São Paulo & 02/10/1986 & $\begin{array}{l}\text { Arqueológico, Etnográfico e } \\
\text { Paisagístico }\end{array}$ \\
\hline Bairro dos Jardins & São Paulo & 23/01/1986 & $\begin{array}{l}\text { Arqueológico, Etnográfico e } \\
\text { Paisagístico }\end{array}$ \\
\hline Casa Modernista & São Paulo & $20 / 10 / 84$ & Histórico \\
\hline $\begin{array}{l}\text { Complexo Ferroviário de } \\
\text { Paranapiacaba }\end{array}$ & Santo André & $30 / 09 / 1987$ & Histórico \\
\hline Vila do Quilombo & Guarujá & $22 / 10 / 88$ & $\begin{array}{l}\text { Arqueológico, Etnográfico e } \\
\text { Paisagístico }\end{array}$ \\
\hline Haras São Bernardo & São Bernardo do Campo & 09/03/1990 & $\begin{array}{l}\text { Arqueológico, Etnográfico e } \\
\text { Paisagístico }\end{array}$ \\
\hline Nascente do rio Tietê & Salesópolis & $21 / 02 / 1990$ & $\begin{array}{l}\text { Arqueológico, Etnográfico e } \\
\text { Paisagístico }\end{array}$ \\
\hline Bairro do Pacaembu & São Paulo & $14 / 03 / 1991$ & $\begin{array}{l}\text { Arqueológico, Etnográfico e } \\
\text { Paisagístico }\end{array}$ \\
\hline $\begin{array}{l}\text { Serra do Guarau e Vila da } \\
\text { Prainha Branca }\end{array}$ & Guarujá & 18/12/1992 & $\begin{array}{l}\text { Arqueológico, Etnográfico e } \\
\text { Paisagístico }\end{array}$ \\
\hline Parque do Ibirapuera & São Paulo & 25/01/1992 & $\begin{array}{l}\text { Arqueológico, Etnográfico e } \\
\text { Paisagístico }\end{array}$ \\
\hline Rocha Moutonnée & Salto & 18/12/1992 & $\begin{array}{l}\text { Arqueológico, Etnográfico e } \\
\text { Paisagístico }\end{array}$ \\
\hline Chácara Tangará & São Paulo & 06/04/1994 & $\begin{array}{l}\text { Arqueológico, Etnográfico e } \\
\text { Paisagístico }\end{array}$ \\
\hline Parque do Povo & São Paulo & 03/06/1995 & $\begin{array}{l}\text { Arqueológico, Etnográfico e } \\
\text { Paisagístico }\end{array}$ \\
\hline Ilhas, ilhotas e lajes & $\begin{array}{l}\text { Bertioga, Caraguatatuba, } \\
\text { Itanhaém, Santos, São } \\
\text { Sebastião e Ubatuba }\end{array}$ & 24/03/1994 & $\begin{array}{l}\text { Arqueológico, Etnográfico e } \\
\text { Paisagístico }\end{array}$ \\
\hline Parque Fernando Costa & São Paulo & $11 / 06 / 1996$ & Histórico \\
\hline Cratera de Colônia & São Paulo & $20 / 08 / 2003$ & $\begin{array}{l}\text { Arqueológico, Etnográfico e } \\
\text { Paisagístico }\end{array}$ \\
\hline $\begin{array}{l}\text { Morro do Juquery e Pico do } \\
\text { Olho d'água }\end{array}$ & São Paulo & $13 / 10 / 2004$ & $\begin{array}{l}\text { Arqueológico, Etnográfico e } \\
\text { Paisagístico }\end{array}$ \\
\hline
\end{tabular}

Fonte: Lista de bens tombados por ordem cronológica-CONDEPHAAT, disponível em www.cultura.sp.gov.br acesso em 18 de abril de 2019 . 
O tombamento das Serras do Japi (1983) e da Serra do Mar (1985) são exemplos de inovação na prática de preservação do CONDEPHAAT, já que a atribuição de valor incide sobre a geomorfologia como justificativa para a preservação do ambiente natural em sua relação dinâmica como os núcleos urbanos. (DETONI, 2016). Destaca-se entre as inovações metodológicas o tombamento do Horto Florestal de Rio Claro (1977), atual Floresta Estadual Edmundo Navarro de Andrade, onde as referências à aclimatação do eucalipto e à oferta de qualidade de vida aos moradores do município foram utilizadas como critérios de valoração unindo a preservação da memória técnico-científica relativa à cultura do eucalipto e à demanda pela fruição da paisagem pela população como justificativa para o tombamento. (PINTO, 2018)

A resolução de tombamento da Serra do Japi explicita essa concepção de preservação, destacando-se a beleza cênica como apenas um dos valores que justificariam sua preservação:

Fica tombada a área abrangida pelas serras do Japi, Guaxinduva e Jaguacoara. Importantes acidentes topográficos e geológicos das serranias de Jundiaí, que, a par com o seu grande valor cênico e paisagístico tem a condição múltipla de banco genético da natureza tropical e de um "castelo de águas" com drenagem radial, comportando-se como área ecológica e hidricamente críticas, dotada de um mosaico de ecossistemas representativos em termos de flora e fauna; e, região capaz de funcionar como espaço serrano regulador para a manutenção da qualidade de vida de um setor de planaltos interiores de São Paulo, sujeitos a forte urbanização e industrialização. O tombamento se faz sob um critério de alto nível de seletividade espacial, envolvendo a preocupação por uma organização induzida do espaço, suficientemente capaz de conciliar preservação e desenvolvimento. (SÃO PAULO, 1983, Art. $1^{\circ}$ )

É notória, no caso do tombamento da Serra do Japi, a mobilização da escala geográfica como justificativa para sua preservação. Como mosaico de ecossistemas e espaço serrano regulador da qualidade de vida na região de Jundiaí, a Serra deveria ser preservada tendo em vista sua relação com a sociedade e, portanto, como patrimônio cultural. (CRISPIM, 2016)

Essa linha argumentativa é sistematicamente utilizada para o tombamento de outros espaços serranos pensados sempre através da perspectiva do planejamento territorial e tendo a cidade como eixo estruturador da prática preservacionista. Assim a resolução de tombamento da Serra do Mar em sua vertente paulista, de 1985, evidencia a amplitude da ação em termos de escala e abrangência social:

Artigo $2^{\circ}$ - O conjunto regional a ser tombado apresenta, ao lado de seu grande valor geológico, geomorfológico, hidrológico e paisagístico, a condição de banco genético de natureza tropical, dotado de ecossistemas representativos em termos de fauna e flora, sendo também região 
capaz de funcionar como espaço serrano regulador para a manutenção das qualidades ambientais e dos recursos hídricos da região litorânea e reverso imediato do Planalto Atlântico Paulista. A escarpa da Serra do Mar, que serviu no passado de refúgio climático para a floresta tropical úmida de encosta, exibe hoje os últimos remanescentes da cobertura florestal original do Estado de São Paulo, fundamentais para a estabilidade das vertentes de altas declividades aí presentes, pouco vocacionadas para as atividades agropastoris em face da sua grande vulnerabilidade ecológica, sujeita que está aos maiores impactos pluviométricos conhecidos no país. (SÃO PAULO, 1985, Art. $2^{\circ}$ )

O tombamento da Serra do Mar cujo processo havia sido aberto em 1979 pelo então representante da cadeira de geografia da USP no CONDEPHAAT José Pereira de Queiroz Neto, sinalizava os choques e esforços de articulação entre o CONDEPHAAT e as instituições de meio ambiente, responsáveis pela administração de um conjunto de parques e reservas em toda a extensão da Serra, pensando assim o tombamento como instrumento de gestão integrada desses espaços:

O tombamento visa prioritariamente articular e consolidar as múltiplas iniciativas do poder público, que vem criando inúmeros parques, reservas e áreas protegidas ao longo desta faixa, do mais alto significado para a preservação da natureza e manutenção da qualidade ambiental. (Idem)
No caso da Serra do Mar o tombamento se deu por sobre as áreas de proteção já existentes como - Parque Estadual da Serra do Mar, unidade de conservação de regime integral instituída em 1977 pela Secretaria Especial do Meio Ambiente (Sema), órgão criado em 1973 no âmbito do então Ministério do Interior somando-se em duplicidade de atribuições ao Instituto Brasileiro de Desenvolvimento Florestal, ambos órgãos fundidos no atual Instituto Chico Mendes de Biodiversidade (ICMbio) vinculado ao Ministério do Meio Ambiente (RIBEIRO; ZANIRATO, 2008). Já em São Paulo, em 1983, foi criado o Conselho Estadual do Meio Ambiente (Consema) e posteriormente, em 1986, a Secretaria Estadual de Meio Ambiente, órgãos responsáveis por gerir as unidades de conservação paulistas a partir das prerrogativas do artigo 193 da Constituição Estadual de 1989 e do Código Florestal brasileiro.

A criação de unidades de conservação, por gerarem a desapropriação de grandes porções territoriais, acabam por promover a remoção de assentamentos humanos de longínqua ocupação nas áreas naturais como são as comunidades caiçaras, os renascentes de quilombos $e$ as aldeias indígenas existentes nos limites da Serra do Mar. Nesse cenário, o tombamento poderia se tornar uma alternativa, já que sua aplicação nos termos do decreto lei 25/37 não implica na desapropriação. 
Dessa forma, destaca-se que a atuação do CONDEPHAAT na proteção da natureza desenvolveu-se em momento imediatamente anterior ao surgimento das primeiras instituições dedicadas à defesa do meio ambiente em São Paulo.

O documento 'Subsídios para um plano sistematizador das paisagens naturais do Estado de São Paulo', publicado como Ordem de Serviço n.1/1982 estabeleceu uma conceituação para paisagem que viria a consolidar as diretrizes de ação do órgão na preservação das áreas naturais:

A paisagem corresponde à globalidade dos componentes naturais articulados num determinado contexto espacial e temporal. Não se confunde com "recurso natural" que implica aproveitamento econômico. Assim, pode se considerar o termo paisagem como síntese das diferentes formas de arranjo e dos diferentes processos de interação dos componentes naturais. (SÃO PAULO, 1982, p. 17)

As Diretrizes de 1982 representam o ápice de uma discussão sobre o patrimônio natural no âmbito do CONDEPHAAT feita com o protagonismo da geografia enquanto campo do saber acadêmico capaz de referenciar práticas de preservação, sobretudo em relação aos conceitos de paisagem e território entendidos nos domínios da ação cultural, embora sejam escassas as fontes sobre o contexto de tessitura desse documento.

O processo de tombamento 20868/79 de tombamento da Serra do Mar apresenta referência à formação de um grupo de trabalho em áreas naturais designado a elaborar diretrizes operacionais para a salvaguarda das áreas naturais que iniciou suas atividades em novembro de 1980 sob a direção da geógrafa e então conselheira da Departamento de Geografia da USP no CONDEPHAAT Lea Goldenstein Compuseram o grupo Gil Sodero de Toledo, indicado pela Geografia da USP, Manuel Carlos de Oliveira, indicado pelo Instituto Geológico de São Paulo, Maria Lagaspe Vieira, indicada pelo Instituto Florestal, Rodolfo Ricardo Geiser e Ricardo Oneken, indicados pela Sociedade Brasileira de Paisagismo. (SÃO PAULO, 1979, fls. 35-36)

Destaca-se nas Diretrizes a precisa definição de critérios de ação que envolviam diversos elementos do mundo natural na sua relação com a dinâmica social:

Art. 1 - Devem ser considerados objetos de interesse para fins de tombamento:

a) Formas de vegetação nativa remanescentes, em especial as áreas onde essa cobertura vegetal esteja ameaçada de extinção eminente;

b) Formas de vegetação secundária que se destacam pelo valor científico ou pela escassez de formas originais;

c) Áreas que se destacam pela existência de monumentos geológicos, de feição geomorfológicas e pedológicas particulares;

d) Áreas cuja paisagem mantém o equilíbrio do sistema ambiental garantindo a manutenção de mananciais (que são feições geológicas e geomorfológicas particulares);

e) Áreas consideradas "habitat" de espécies animais raras; 
f) Paisagens que constituem exemplos de atuação antrópica, efetuada através de manejos que levam em conta a preservação do espaço territorial e das estruturas sociais locais;

g) Toda paisagem alterada ou não pela ação antrópica que se caracterize pela sua expressividade, raridade e beleza excepcional, e pelo que a mesma representa em termos de interesse turístico, social e científico.

Para Scifoni (2006) a influência do debate acadêmico sobre o conceito de paisagem na geografia francesa de então é percebido nas definições firmadas pelo CONDEPHAAT em 1982 a partir da obra de George Bertrand (1978), renomado geógrafo francês estudioso da paisagem como geosistema complexo. Compreendendo entre suas definições a percepção de que a paisagem é um fenômeno inscrito na história, um produto da história social, movido por forças do sistema de produção, que definem por meio da produção material, o seu conteúdo; um produto econômico e cultural integrado a um sistema social, mas ela não cessa de aparecer e de funcionar como um sistema ecológico (Bertrand, 1978, p. 253 Apud SCIFONI, 2006, p. 48)

Outras referências à geografia francesa podem ser encontradas no processo 20868/79 de tombamento da Serra do Mar fator que evidencia a capilaridade do debate estabelecido entre os geógrafos na instrução de processos e elaboração de resoluções de tombamento. Em
1985 quando do estabelecimento dos critérios finais de preservação da Serra do Mar que recomendaram a formação de uma comissão interórgãos para sua gestão junto a Secretaria Estadual do Meio Ambiente e á Cetesb foram listadas as obras citadas nos estudos técnicos e pareceres elaborados ao longo do processo:

Bertrand, Georges. Paysage et Géographie des Pyrenées et du Sud-Ouest, Tome 39, Fasc. 3, Toulouse, 1968 p. 249-272;

Erthart, Henri (1967) La genése des sols en tant que Phénomène géologique. Esquisse d'une théorie - géologique et geochimique. Exemples d'application, Paris, 2 ed., 1967 p. 177 (SÃO PAULO, 1979, fl. 128)

Em 1983 quando a demanda de estudos de tombamento de áreas naturais tornava-se crescente no CONDEPHAAT foram reunidas condições favoráveis à criação de uma Equipe de Áreas Naturais como núcleo de apoio do Serviço Técnico de Conservação e Restauro. De caráter interdisciplinar, a equipe se constituía de geógrafos, engenheiros agrônomos, biólogos, entre outros agentes que se tornaram responsáveis por gerir o patrimônio paisagístico tombado e propor novas ações da mesma natureza (SCIFONI, 2006, p. 149).

O início dos trabalhos da equipe foi favorecido pelo legado deixado por Aziz Ab'Saber não só pela elaboração, quando conselheiro do órgão, das "Diretrizes para uma política de preservação 
das reservas naturais do Estado de São Paulo" (1977), mas também por sua passagem pela presidência do órgão ocorrida entre novembro de 1982 e março de 1983, quando empreendeu um esforço de aparelhamento do CONDEPHAAT para atender a demanda por conhecimento técnico e acadêmico especializado para o tratamento das áreas naturais. (CRISPIM, 2016 p. 172)

Atuante entre 1983 e 1995 a equipe contou com o trabalho de profissionais oriundos de diversas áreas num esforço coletivo de resistência e renovação conceitual das práticas do patrimônio paulista. A primeira equipe era formada apenas por quatro membros: o geógrafo Wilson Morato, a bióloga Sueli ngelo Furlan e dois antropólogos, José Guilherme Cantor Magnani e Virgínia Valadão; a partir de 1986 ingressaram na equipe o biólogo Francisco de Arruda Sampaio e Luis Paulo Ferraz, geógrafo. De 1988 a 1995, período de maior crise de suas atividades conforme informa Scifoni (2006), compuseram a Equipe o ecólogo Roberto Varjabedian, a geóloga Maria Cristina Scalope, o biólogo Denis Euri e os geógrafos Simone Scifoni, Antônio Carlos Sampaio, Eliane Del Vecchio e Rodrigo Cerqueira Nunes. (FURLAN, 2018, p .67 e SCIFONI, 2006 p. 49)

A extinção da equipe de áreas naturais em 1995 por ato deliberado do governo do estado, mesmo que ainda sejam desconhecidas as especificidades do contexto que resultou nessa decisão, eminentemente autoritária, consolidou um cenário de abandono das ações de preservação de áreas naturais pelo qual o órgão perdeu sua capacidade técnica de responder às demandas relativas ao patrimônio natural. Conforme Scifoni (2006) essa visão se consolida num cenário de desregulamentação e exclusão do patrimônio natural, negando a conquista histórica representada pela incorporação dessa concepção às práticas patrimoniais. (SCIFONI, 2006, p. 157)

Nesse sentido, quando a natureza deixa de ser patrimônio cultural perde também o seu caráter dinâmico como suporte de memória para os diferentes grupos formadores do território perdendo-se de vista a historicidade da construção da paisagem. Conforme nos alerta Furlan (2018) as áreas naturais tombadas "representam um conjunto de permanências de tempos da natureza e tempos da cultura que interessam à sociedade", de forma abrangente (FURLAN, 2018, p. 71), o que se fazia possível mediante a ideia de proteção do espaço total, nos termos de Ab'Saber (1977):

O princípio geral da proteção de áreas naturais pelo estatuto do tombamento foi proteger a paisagem como espaço total de remanescentes com as marcas culturais, protegendo o que não deve ser "apagado" pela supremacia dos interesses exclusivamente econômicos que, na aceleração do mercado, rapidamente eliminam as paisagens lentas, significativas e relevantes. A aceleração contemporânea elimina as marcas 
históricas, geomorfológicas, biogeográficas e culturais. Foi uma visão fortemente inovadora para o patrimônio e do vínculo com a cultura viva, a mais viva possível (FURLAN, 2018, p. 74)

A busca pela construção de uma política de preservação de áreas naturais entre as décadas de 1970 e 1990 é um capítulo da história da instituição do patrimônio paulista que se expressa pela ação de muitos agentes entre técnicos e conselheiros do CONDEPHAAT e pelas lutas da sociedade civil que viam no direito ao ambiente urbano e ao ambiente natural as bases de um Estado democrático.

O tombamento, figura jurídica historicamente associada à preservação do patrimônio edificado, no caso das áreas naturais, atuava como sendo uma possibilidade de intervenção direta na escala de valores atribuídos ao território em que o valor cultural possibilitaria a construção de pactos sociais em prol da preservação da paisagem. Assim, a perda de referências conceituais e da memória das ações desenvolvidas desde 1976 com as "Diretrizes para uma política de preservação das reservas naturais do Estado de São Paulo" (Ab'Saber, 1977), compreendendo a atuação de outros conselheiros representantes do campo da geografia como Augusto Humberto Titarelli, José Pereira de Queiroz Neto e Lea Goldenstein, como também da Equipe de Áreas Naturais produz um espaço de interrogação na história do CONDEPHAAT, espaço esse que, em se tratando de memória subterrânea, tende sempre a ressurgir desafiando velhos paradigmas do campo do patrimônio cultural.

Portanto, a atualidade da reflexão sobre a proteção da natureza pelos órgãos de preservação do patrimônio cultural se faz presente no rememorar das ações do órgão paulista, CONDEPHAAT, na tomada de decisão pela salvaguarda dos espaços naturais percebidos e refletidos na história da formação da cultura dos diferentes grupos formadores da sociedade. O tombamento dos espaços naturais, considerando assim o termo paisagem como recurso de enunciação de novos saberes patrimoniais, constitui-se como termômetro do fortalecimento da democracia e do pleno exercício do direito à memória e à qualidade de vida estabelecidos na Constituição Cidadã de 1988. Retomar o debate sobre a viabilidade de sua aplicação é uma forma de combater o obscurantismo que atravessam as políticas públicas no Brasil.

\section{Referências bibliográficas}

AB'SABER, Aziz Nacib. Diretrizes para uma política de preservação das reservas naturais do Estado de São Paulo; Boletim de Geografia e Planejamento. São Paulo. n.30 p.7-19, 1977.

O Tombamento da Serra do Mar no Estado de São Paulo. Revista do Patrimônio Histórico e Artístico Nacional. n.21. Brasília: 1986. 
ANDRADE, Mário de. Anteprojeto de lei criando o Serviço do Patrimônio Artístico Nacional. In: SPHAN/PRO-MEMÓRIA. Proteção e revitalização do patrimônio cultural no Brasil: Uma trajetória. Brasília: Sphan/FNPM, 1980, p. 90-106.

CAUQUELIN, Anne. A invenção da paisagem. São Paulo: Martins Fontes, 2007.

CHUVA, Márcia Regina Romeiro. Os arquitetos da memória: sociogênese das práticas de preservação do patrimônio cultural no Brasil (1930-1940). Rio de Janeiro: UFRJ, 2009.

CRISPIM, Felipe Bueno. Entre a Geografia e o Patrimônio: Estudo das ações de preservação das paisagens paulistas pelo CONDEPHAAT (1969-1989). São Bernardo do Campo: EdUFABC, 2016.

DETONI, Sandro Francisco. Natureza e Patrimônio Cultural: a geomorfologia como referencial metodológico no tombamento de áreas naturais. Tese (Doutorado em Geografia Física), Faculdade de Filosofia Letras e Ciências Humanas, Universidade de São Paulo, São Paulo, 2016.

FONSECA, Maria Cecília Londres. 0 patrimônio em processo: trajetória da política federal de preservação no Brasil. Rio de Janeiro: UFRJ/ Iphan, 2009.
FURLAN, Sueli Angelo. Áreas naturais tombadas e a proteção da paisagem. Revista do Centro Preservação Cultural da Universidade de São Paulo Edição Especial 50 anos do CONDEPHAAT, São Paulo v.13 n.26 p. 63-93 out/dez 2018.

MAGALHÂES, Cristiane. 0 desenho da história no traço da paisagem: patrimônio paisagístico e jardins históricos no Brasil - memória, inventário e salvaguarda. Tese (Doutorado em História). Instituto de Filosofia e Ciências Humanas, Universidade Estadual de Campinas, Campinas, 2015.

MCCORMICK, John. Rumo ao paraíso. A história do movimento ambientalista. Rio de Janeiro: Relume-Dumará, 1992.

MONGELLI, Mônica de Medeiros. Natureza e cultura: práticas de preservação patrimonial no Brasil. Dissertação (Mestrado em Arquitetura e Urbanismo) - Faculdade de Arquitetura e Urbanismo, Universidade de Brasília, Brasília, 2011.

NASCIMENTO. Flávia Brito. Formar ou questionar? Os cursos de especialização em patrimônio cultural na década de 1970. Anais do Museu Paulista, São Paulo, v.24 n.1, 2016. 
PEREIRA, Danilo Celso. Paisagem como

Patrimônio: entre potencialidades e desafios para a implementação da Chancela da Paisagem Cultural Brasileira. Dissertação (Mestrado Profissional em Preservação do Patrimônio Cultural). Instituto do Patrimônio Histórico e Artístico Nacional. Rio de Janeiro, 2018.

PINTO, Júlia Amabile Aparecida de Souza. História e Patrimônio Ambiental: um estudo da Floresta Edmundo Navarro de Andrade, Rio Claro - SP (1974-2002). Dissertação (Mestrado em História). Escola de Filosofia Letras e Ciências História Unifesp, Guarulhos. 2018.

RIBEIRO, Rafael Winter. Paisagem Cultural e Patrimônio. Série Pesquisa e Documentação, Rio de Janeiro: Instituto do Patrimônio Histórico e Artístico Nacional, 2007.

RIBEIRO, Wagner Costa; ZANIRATO, Silvia Helena. Ordenamento jurídico para a proteção do patrimônio natural no Brasil. Revista Brasileira de História n.158, 2008.

RODRIGUES, Marly. Imagens do passado: a instituição do patrimônio em São Paulo (19681987). São Paulo: Editora Unesp, 2000.

SÃO PAULO. Processo CONDEPHAAT 20868/79 Tombamento da Serra do Mar e de Paranapiacaba, São Paulo: Secretaria de Cultura, 1979.
Resolução Secretaria da Cultura

n.40/85, São Paulo: Secretaria de Cultura , 1985.

Resolução da Secretaria de Cultura n.11/83, São Paulo: Secretaria de Cultura, 1983.

Subsídios para um plano Sistematizador das Paisagens Naturais do Estado de São Paulo, São Paulo: Secretaria de Cultura, 1982.

Lei 10247: Dispõe sobre a competência, organização e funcionamento do Conselho de Defesa do Patrimônio, Histórico, Arqueológico, Artístico e Turístico do Estado de São Paulo e dá outras providências. São Paulo: Assemblélia Legislativa do Estado de São Paulo, 1968.

SCIFONI, Simone. A construção do patrimônio natural. Tese (Doutorado em Geografia Humana), Faculdade de Filosofia, Letras e Ciências Humanas, Universidade de São Paulo, São Paulo, 2006.

UNITED NATIONS EDUCATIONAL, SCIENTIFIC AND CULTURAL ORGANIZATION. Convenção do Patrimônio Mundial, Cultural e Natural. Paris: Unesco, 1972. 